\title{
Understanding Reading Anxiety: New Insights from Neuroscience
}

\author{
Mary Renck Jalongo $・$ Rae Ann Hirsh
}

Published online: 13 March 2010

(C) Springer Science+Business Media, LLC 2010

\begin{abstract}
Recent advances in research have furthered understanding of the many roles that emotions play in fostering effective learning. This editorial argues, against fashion, that the affective domain is neither separate from nor less significant in the learning process than the cognitive domain. It begins with a vignette of a struggling reader. It then defines emotions and explains their role in learning, using cognitive psychology and neuroscience as the research base. Next, it examines the influence of the affective domain on learning to interpret symbols. The editorial concludes with an analysis of reading anxiety and recommendations for practice.
\end{abstract}

Keywords Learning - Emotions - Reading anxiety · Affective domain $\cdot$ Brain research

A second grader named Mark reads aloud, the very picture of impulsive style. Although he painstakingly sounds out the first couple of words, that effort is followed by a rush of words - even nonwords - that bear little resemblance to the print on the page. Mark appears to realize that comprehension has been lost. His freckled face begins to flush with embarrassment and his hands begin to tremble.

This child approaches the task of reading with the same expectation of pain and grim determination that is summoned up before pulling off a bandage. When Mark's tutor asks him to say something about himself, it is clear he and his family have been stunned by his placement in a learning support class at his new school. Mark says softly, "I know I was smart in kindergarten and I think I was still smart in

M. R. Jalongo $(\square) \cdot$ R. A. Hirsh

Indiana, PA, USA

e-mail: mjalongo@iup.edu first grade, but then..." His voice sounds wistful as he says softly, "I just don't know what happened to me."

What has happened to this child, once confident and competent, now floundering amidst intensive efforts to remediate his reading difficulties? Researcher Sulzby (1985) concluded that children who are deluged with reading instruction can become "hopelessly confused" about what it is that they are expected to do. Mark's has not only demonstrated this confusion but also has begun to expand his repertoire of coping strategies. At the next tutoring session, he arrives with a thick encyclopedia about dogs, written in technical language that would send many adults to the dictionary. His tutor gently asks if this is the book that his teacher selected for him to read. No, he admits, it is not—but he really wants to look the pictures. Lately, Mark has been trying to avoid reading altogether with questions, bathroom breaks, pencil sharpening, and misplaced books.

This child's behavior illustrates what happens when our good intentions and concerted efforts to improve reading skills fail. The professionals in this scenario operate on the assumption that Mark is lacking certain skills, that he somehow "missed" important learnings, so adults say it again, louder and more forcefully this time. Selma Wassermann (2004) hits the mark when she looks back on her career as a reading teacher and concludes that something else is responsible:

Giving more credibility to the diagnostic tools than they deserved, I painstakingly recorded formative and summative information about the results and about each student's performance at each instructional session. In retrospect, I see this more as a legitimization of the process than as actually helpful to students... 
In nearly all cases, there was no evidence that the children's teachers had failed them in the teaching of "reading skills." These had been taught, with dedication and concern-but not learned.

It wasn't until many years, many experiences later, that I learned about "fear" of reading-like "fear of flying"-finding that some children, for whatever reason, were terrified of performing in this particular curriculum area, that some children felt so disempowered that they were afraid to try. (Wassermann 2004, pp. 39-40)

A connection between fear and learning is much more than one reflective practitioner's observation, however. Contemporary neuroscience helps to explain how it happens. We know that the major networks of the brain are interconnected so, when a child reads, the recognition network identifies letters and words while the strategic network simultaneously focuses on understanding the text and monitors progress toward that goal. At the same time, the affective network - that seat of emotions known as the limbic system-activates such things as interest, motivation, anxiety, and so forth (Hinton et al. 2008). Far from acting independently in the old "right brain/left brain" way that is now known to be inaccurate, the affective or limbic system is interconnected with cortical areas involved in cognitive processing (Le Doux 2000).

Reading and fear get connected in the same way that classical conditioning operates. An initially neutral stimulus (e.g., reading aloud) is repeatedly paired with a noxious unconditioned stimulus (e.g., teacher judgment, peer ridicule) and, as a result of this pairing, the learner forms an association between reading and negative emotions. Suppose that a child who struggles with reading is called upon to read a passage of text aloud. The task activates the amygdale, the part of the brain which elicits an immediate sense of dread and fear. At the same time, a "slower, cortically driven cognitive appraisal of the situation is occurring: various thoughts converge to a cognitive confirmation that this is a threatening situation" and this causes a rising sense of alarm (Hinton et al. 2008, p. 91).

The child might relive the embarrassment of fumbling over words earlier in the week, panic at the sight of several unfamiliar words in the passage, sense the teacher's growing impatience, or hear a peer whisper "Hurry up, it's almost time for lunch." As the feelings of worry and alarm mount, and images of worst-case scenarios escalate, the ability to concentrate is seriously compromised. These emotions based on self-evaluation are referred to as appraisal emotions (Roseman and Smith 2001). It is important to note that appraisal emotions are the result of the child's perceptions of those interactions and events, not necessarily the interactions/events themselves (Silvia
2005). Thus, it would be possible for six children to be in the same reading group and each could have different appraisal emotions of the identical interactions and events; appraisal emotions are subjective. Appraisal emotions exert a profound effect on motivation and persistence at tasks. Students with negative appraisal emotions tend to give up quickly while those with positive appraisal emotions are more apt to tackle challenging tasks and work toward a solution (Frenzel et al. 2007).

Consider what happens when, day after day, such experiences are repeated. School settings routinely require children to violate their natural instincts to preserve selfesteem by insisting that they pursue tasks at which they have little hope for success. Children who struggle with reading are immersed in material well beyond their current capabilties and, as frustration builds, the curriculum undermines the child's competence and confidence. Thus, Mark had learned he was not very smart, not a good reader, and an object of pity or ridicule within the academic environment. He had developed reading anxiety.

\section{How Is Emotion Defined and How Does It Affect Learning?}

An emotional state is characterized by the chemical balance, posture, and respiratory patterns of person in a given period of time (Jensen 2005). Although there are hundreds of emotional states, the ones most commonly seen in the classroom are joy/pleasure, anticipation/curiosity, fear/ threat, and sadness/disappointment (Schutz and Pekrun 2007). Positive learning states_-such as joy and anticipation-encourage intellectual arousal and help the brain attend to, relate, and store the new information in long-term memory. Positive emotions also broaden thought processes and enhance productivity because they maximize the 'visual work form area' (VWFA) - the "mental workspace" available for reasoning processes (Hinton et al. 2008; Izard 2007). Increases of dopamine in the brain are linked to positive emotions; dopamine is the naturally occuring chemical that produces feelings of well-being and euphoria (Fredrickson 2001). Positive emotions such as joy, interest, and feelings of mastery motivate children to explore, to learn, to be open to new information, and to participate in activities (Fredrickson and Branigan 2005).

Conversely, negative emotions (e.g., fear, sadness, disappointment) reduce the brain's ability to attend to and process new information because the brain is swamped with the task of exercising control over powerful emotions. Prolonged negative states increase cortisol and other hormones in the brain and can eventually lead to damage to the hippocampus, which directly affects the brain's ability 
to convert information from short-term memory to longterm memory storage (Jensen 2005).

Greenspan (1997) refers to emotions as the "architect of the mind" because they play such a crucial role in building the academic constructs necessary for future learning. We know that emotions develop through social interactions, have an important role in cognitive development, and change with experience and interaction (Eynde and Turner 2006; Pekrun 2006; Scherer 2000). "Over 2,000 years ago, Plato declared that all learning has an emotional base, but it is only recently that neuroscientists have begun to uncover the biological interdependence of learning and emotion ... brain research reveals that emotion is fundamental to learning and instruction that neglects emotional dimensions of learning is likely to be ineffective" (Hinton et al. 2008, p. 90, 100). Contrary to popular opinion, emotions are not byproducts of learning; rather, they are an integral part of the learning process (Eynde and Turner 2006). Therefore, taking the affective domain into consideration is not way of coddling children. It is a response to a burgeoning body of evidence on the brain, mind, and learning (Falk 2009).

Research documents that:

- Emotions influence thought in powerful ways that can initiate, stop, or hasten information processing (Izard 2007).

- Emotions determine whether children approach or avoid a learning situation and how much effort they put into the task (Jalongo 2007).

- Emotions serve to focus attention and organize recall and memory; children pay more attention to things with emotional significance and tend to remember details of emotionally powerful experiences (Kensinger 2007).

- Too much emotion or negative emotions can interfere with information processing because the brain is consumed with the task of suppressing intense emotions (Fenske and Raymond 2006).

\section{What Is the Role of Emotions in Learning to Read?}

Emotions facilitate symbol development, create meaning, drive attention, and have their own memory pathways (Jensen 2005; Greenspan and Shanker 2004). Symbol systems such as images, letters, words, and punctuation marks provide the necessary foundation for reading skills. The mastery of multiple symbol systems optimizes a child's potential and intelligence. Greenspan (1997) defines the basic unit of intelligence as "the connection between a feeling or a desire and an action or a symbol" [p. 16]. But how does a child create and assign meaning to symbols? Without emotions, the symbols used in a child's environment have little meaning or usability. Emotions allow the brain to make sense of and give meaning to print (Izard et al. 2001). The meaning of a symbol is constructed gradually; it changes with the interactions the child has with that symbol in the environment. In order for a symbol to develop that is meaningful and usable, it needs to be encoded in the brain with an emotion (Greenspan and Shanker 2004). Thus, the ability to interpret symbols does not operate independently of emotions, as so many efforts as remediation might suggest. Children learn to use the symbols of language within socio-historical interactions that occur in the context of relationships (Calkins 2003; Eynde and Turner 2006; Eynde et al. 2006; Fox et al. 2005).

Emotions also assist in other areas of literacy. Readers naturally make emotional inferences as they read to make sense of characters and plot in stories (Gygax et al. 2007). Emotions provide a critical tool in comprehending print because they provide value, meaning, and strategies when problem solving (Eynde et al. 2006). Therefore, optimal development depends on environments where adults create healthy relationships with children (Zembylas 2005) and where positive emotional states predominate (Jensen 2005).

\section{What Is Reading Anxiety?}

Over the years an array of labels has been used to describe children and their issues with reading: "poor readers", "reluctant readers", "illiterate", "children who read below grade level", "students at risk of reading failure", "struggling readers", and "children with reading difficulties", to name a few. All of these descriptors hint at blaming the child while none of them suggests any emotional basis for the phenomenon yet, as we have argued thus far in this editorial, the anxieties, fears, and phobias precipitated by reading tasks are a major impediment to reading progress.

Here is a brief overview of what psychologists now know about anxiety:

- Anxiety is a negative emotion that impairs learning.

- Whereas fear is a response to present or imminent threats, anxiety is a fear response to imagined or distant threats.

- Anxiety is a feeling of helplessness focused on future threats or threats to self-esteem.

- Anxiety disorders are not only among the most common during childhood but also the earliest to emerge.

- When anxiety becomes intense it undermines children's ability to pay attention.

- The term phobia generally is reserved for more intense and generalized responses to imagined threats. 
Using these definitions helps to explain why children's negative emotional responses toward reading are referred to variously as fear, anxiety, or phobia-it might be any of the above, depending upon the intensity, duration and the extent to which it causes the reader to shut down. It is not far fetched for reading - particularly reading aloud_- to be a source of anxiety for children. Even among adults, public speaking is fear \#2-right after physical harm such as death, disease, and accidents. Reading aloud is public speaking combined with the performance pressure of onthe-spot decoding accuracy, coupled with evaluation by teachers and peers. Little wonder, then, that when children are called upon to read aloud in public, even those without reading difficulties evidence an increase in blood pressure and a quickened pulse (Lynch 2000).

As Zbornik (2001) explains, reading anxiety is a specific, situational phobia toward the act of reading that has physical and cognitive reactions. Physical reactions to anxiety include the release of adrenaline ("fight or flight reaction") and physical symptoms, such as sweating, feeling shaky or faint, a pounding heart, rapid breathing, "butterflies" in the stomach, a tension headache, a stomachache, or even throwing up. Cognitive reactions to anxiety include an overwhelming sense of dread, low selfesteem, feelings of helpless, and expectations of public humiliation. These physical and cognitive reactions also interact, as when a child thinks, "My hands are shaking." or "I know my face is getting red." As the child becomes overhwhelmed by emotions and worries (e.g., "What if the other kids laugh at me?") it leaves few cognitive reserves to deal with the task of decoding and comprehending print.

Some questions that have been used to assess reading anxiety in students include items such as:

- What do you think about when someone asks you to read out loud? What goes through your mind?

- What do you worry about when you are asked to read?

- How does your body feel when reading? Do you sweat? Does your stomach get upset? Do you get headaches? Do you feel jittery/nervous?

- Do you seem to know the answers when reading by yourself but cannot remember the words when you have to read them out loud? (Zbornik 2001).

\section{What Can Be Done to Alleviate Reading Anxiety?}

As Zembylas (2005) points out, "Emotion is the least investigated aspect of research on teaching, yet it is probably the aspect most often mentioned as being important and deserving more attention"[p.466]. Facilitating positive emotional states in the classroom encourages more positive self-evaluations (i.e., appraisal emotions in the child].
Positive appraisal emotions can help the child be more receptive to learning and overcome negative emotional experiences and/or expectations (Amsterlaw et al. 2009).

Psychologist Zbornik (2001) offers advice to practitioners and families about appropriate responses to children's reading anxiety. If children give up quickly, try to pique curiosity by identifying the child's interests and questions, encouraging reading efforts, and emphasizing the usefulness of reading. If children refuse to read, structure reading tasks for success, plan activities that associate pleasure with reading, and provide opportunities to choose and discuss topics with someone they respect. And, if children are afraid they cannot accomplish reading tasks independently, promote their self-confidence by starting small, increasing the challenge very gradually, and pairing them with peers or tutors.

Without a doubt, emotions play a role in learning to read; therefore, it is imperative to facilitate a learning environment that supports the healthy development of emotion in children. Three important points can be deduced from the research reviewed here. First, that anxieties, fears, and phobias associated with the task of reading truly exist; second, that learning to read activates both the cognitive and affective parts of the brain; and finally, that attention to providing positive emotional states is a powerful way of improving children's overall school performance (Amsterlaw et al. 2009; Croizet and Dutrevis 2004; Eynde et al. 2006; Feldman 2007; Gygax et al. 2007; Havighurst et al. 2004; Osborne 2007; Schutz and Davis 2000; Yeh 2008; Zembylas 2005).

\section{Conclusion}

Too often, children like Mark who struggle with reading are referred to as "outliers." Their scores distance them from the rounded portion of a normal curve bell curve and position them well below their peers on percentile ranks. Then, as if this were not bad enough, these children become outliers, not only in terms of their test scores but also at the human level as adults lose faith in their capacity to learn and the children lose faith in themselves. In school systems' relentless pursuit of better scores on state-mandated tests, children who struggle with reading are viewed with decreasing understanding and little compassion. They defy educators' curative powers, bring down the averages, and threaten job security-even the future of the school itself. Frustrated in their attempts, educators who are all about skills and strategies are eager to find something or someone to effect a remedy. What is less well understood is that, until or unless they consider the affective realm, children's progress in reading-most especially the progress of children with reading anxiety-will remain stalled. 


\section{References}

Amsterlaw, J., Lagattuta, K., \& Meltzoff, A. (2009). Young children's reasoning about the effects of emotional and physiological states on academic performance. Child Development, 80(1), 115-133. doi:10.1111/j.1467-8624.2008.01249.x.

Calkins, S. (2003). Temperament and emotional regulation: Multiple models of early development. In M. Beauregard (Ed.), Advances in consciousness research (pp. 47-71). Amsterdam, The Netherlands: John Benjamins.

Croizet, J., \& Dutrevis, M. (2004). Socioeconomic status and intelligence: Why test scores do not equal merit. Journal of Poverty, 8(3), 91-107. doi:10.1300/J134v08n03-05.

Eynde, P., Corte, E., \& Verschaffel, L. (2006). Accepting emotional complexity: A socio-constructivist perspective on the role of emotions in the mathematics classroom. Educational Studies in Mathematics, 63(2), 193-207. doi:10.1007/s10649-006-9034-4.

Eynde, P., \& Turner, J. (2006). Focusing on the complexity of emotion issues in academic learning: A dynamical component systems approach. Educational Psychology Review, 18(4), 361376. doi:10.1007/s10648-006-9031-2.

Falk, B. (2009). Teaching the way children learn. New York, NY: Teachers College Press.

Feldman, R. (2007). On the origins of background emotions: From affect synchrony to symbolic expression. Emotion, 7(3), 601611. doi:10.1037/1528-3542.7.3.601.

Fenske, M. J., \& Raymond, J. E. (2006). Affective influences of selective attention. Current Directions in Psychological Science, $15,312-316$.

Fox, N. A., Henderson, H. A., Marshall, P. J., Nichols, K. E., \& Ghera, M. M. (2005). Behavioral inhibition: Linking biology and behavior within a developmental framework. Annual Review of Psychology, 56, 235-262. doi:10.1146/annurev.psych.55. 090902.141532

Fredrickson, B. L. (2001). The role of positive emotions in positive psychology: The broaden-and-build theory of positive emotions. American Psychologist, 56, 218-226.

Fredrickson, B. L., \& Branigan, C. (2005). Positive emotions broaden the scope of attention and thought-action repertoires. Cognition and Emotion, 19, 313-332.

Frenzel, A., Pekrun, R., \& Goetz, T. (2007). Girls and mathematicsA "hopeless" issue? A control-value approach to gender differences in emotions towards mathematics. European Journal of Psychology of Education, 22(4), 497-514. Retrieved from http://www.ispa.pt/ejpe/.

Greenspan, S. (1997). The growth of the mind and the endangered origins of intelligence. Cambridge, MA: Da Capo Press.

Greenspan, S., \& Shanker, S. (2004). The first idea: How symbols, language, and intelligence evolved from our primate ancestors to modern humans. Cambridge, MA: Da Capo Press.

Gygax, P., Tapiero, I., \& Carruzzo, E. (2007). Emotion inferences during reading comprehension: What evidence can the self-pace reading paradigm provide? Discourse Processes: A Multidisciplinary Journal, 44(1), 33-50. doi:10.1080/01638530701285564.

Havighurst, S. S., Harley, A., \& Prior, M. (2004). Building preschool children's emotional competence: A parenting program. Early Education and Development, 15(4), 423-448. Retrieved from http://www.erlbaum.com.

Hinton, C., Miyamoto, K., \& Della-Chiesa, B. (2008). Brain research, learning and emotions: Implications for education research, policy and practice. European Journal of Education, 43(1), 87-103.

Izard, C. E. (2007). Basic emotions, natural kinds, emotion schemas, and a new paradigm. Perspectives on Psychological Science, 2, 206-280.
Izard, C., Fine, S., Schultz, D., Mostow, A., Ackerman, B., \& Youngstrom, E. (2001). Emotion knowledge as a predictor of social behavior and academic competence in children at risk. Psychological Science, 12(1), 18-23. doi:10.1111/1467-9280. 00304.

Jalongo, M. R. (2007). Beyond benchmarks and scores: A reassertion of the role of motivation and interest in academic achievement. Childhood Education (An Association for Childhood Education International Position Paper). Available: http://www.acei.org/ motivPosPaper.pdf.

Jensen, E. (2005). Teaching with the brain in mind (2nd ed.). Alexandria, VA: Association for Supervision and Curriculum Development.

Kensinger, E. A. (2007). Negative emotions enhances memory accuracy: Behavioral and neuroimaging evidence. Current Directions in Psychological Sciences, 16, 213-218.

Le Doux, J. (2000). Emotion circuits in the brain. Annual Review of Neuroscience, 23, 155-184.

Lynch, J. J. (2000). A cry unheard: New insights into the medical consequences of loneliness. Baltimore, MD: Bancroft Press.

Osborne, J. (2007). Linking stereotype threat and anxiety. Educational Psychology, 27(1), 135-154. doi:10.1080/01443410601 069929.

Pekrun, R. (2006). The control-value theory of achievement emotions: Assumptions, corollaries, and implications for educational research and practice. Educational Psychology Review, 18(4), 315-341. doi:10.1007/s10648-006-9029-9.

Roseman, I., \& Smith, C. (2001). Appraisal theory: Overview, assumptions, varieties, controversies. In K. Scherer, A. Schorr, \& T. Johnstone (Eds.), Appraisal processes in emotion: Theory, methods, research (pp. 3-19). New York: Oxford University Press.

Scherer, K. (2000). Emotions as episodes of subsystem synchronization driven by nonlinear appraisal process. In M. Lewis \& I. Granic (Eds.), Emotion, development, and self-organization: Dynamic systems approaches to emotional development (pp. 70-99). New York: Cambridge University Press. Retrieved from http://www.affective-sciences.org/node/638.

Schutz, P. A., \& Davis, H. (2000). Emotions and self-regulation during test taking. Educational Psychologist, 35(4), 243-256. Retrieved from http://www.erlbaum.com/Journals/journals/EP/ ep.htm.

Schutz, P. A., \& Pekrun, R. (Eds.). (2007). Emotion in education. Burlington, MA: Academic Press/Elsevier.

Silvia, P. (2005). Emotional responses to art: From collation and arousal to cognition and emotion. Review of General Psychology, 9(4), 342-357. doi:10.1037/1089-2680.9.4.342.

Sulzby, E. (1985). Children's emergent reading of favorite storybooks: A developmental study. Reading Research Quarterly, 20, 458-481.

Wassermann, S. (2004). This teaching life: How I taught myself to teach. New York, NY: Teachers College Press.

Yeh, Y. (2008). Age, emotion regulation strategies, temperament, creative drama, and preschoolers' creativity. Journal of Creative Behavior, 42(2), 131-148. Retrieved from http://www.creative educationfoundation.org/.

Zbornik, J. (2001). Reading anxiety manifests itself emotionally, intellectually. Today's School Psychologist. Available: http:// www.lkwdpl.org/schools/specialed/zbornik3.htm.

Zembylas, M. (2005). Beyond teacher cognition and teacher beliefs: The value of the ethnography of emotions in teaching. International Journal of Qualitative Studies in Education, 18(4), 456-487. doi:10.1080/09518390500137642. 